\title{
Low physical activity, high television viewing and poor sleep duration cluster in overweight and obese adults; a cross-sectional study of 398,984 participants from the UK Biobank
}

\author{
Sophie Cassidy ${ }^{1 *}$ (D), Josephine Y. Chau ${ }^{2}$, Michael Catt ${ }^{3}$, Adrian Bauman ${ }^{2}$ and Michael I. Trenell ${ }^{1}$
}

\begin{abstract}
Background: An unhealthy lifestyle is one of the greatest contributors to obesity. A number of behaviours are linked with obesity, but are often measured separately. The UK Biobank cohort of $>500,000$ participants allows us to explore these behaviours simultaneously. We therefore aimed to compare physical activity, television (TV) viewing and sleep duration across body mass index (BMI) categories in a large sample of UK adults.

Methods: UK Biobank participants were recruited and baseline measures were taken between 2007 and 2010 and data analysis was performed in 2015. BMI was measured objectively using trained staff. Self-report questionnaires were used to measure lifestyle behaviours including the international physical activity questionnaire (IPAQ-short form) for physical activity. During data analysis, six groups were defined based on BMl; 'Underweight' $(n=2026)$, 'Normal weight' $(n=132,372)$, 'Overweight $(n=171,030)$, 'Obese I' $(n=67,903)$, 'Obese II' $(n=18,653)$ and 'Obese III' $(n=7000)$. The odds of reporting unhealthy lifestyle behaviours (low physical activity, high TV viewing or poor sleep duration) were compared across BMI groups using logistic regression analysis.
\end{abstract}

Results: Overweight and obese adults were more likely to report low levels of physical activity ( $\leq 967.5 \mathrm{MET}$.mins/wk) ('Overweight'-OR [95\% Cl]: 1.23 [1.20 to 1.26], 'Obese I' 1.66 [1.61-1.71], 'Obese II' 2.21 [2.12-2.30], and 'Obese III' 3.13 [2.95 to 3.23]) compared to 'Normal weight' adults. The odds of reporting high TV viewing ( $3 \mathrm{~h} /$ day) was greater in 'Overweight' (1.52 [1.48 to 1.55]) and obese adults ('Obese l' 2.06 [2.00-2.12], 'Obese II' 2.69 [2.58-2.80], 'Obese III' 3.26 [3.07 to 3.47]), and poor sleep duration ( $<7,>8 \mathrm{~h} /$ night) was higher in 'Overweight' (1.09 [1.07 to 1.12]) and obese adults ('Obese I' 1.31 [1.27-1.34], 'Obese II' 1.50 [1.44-1.56], 'Obese III' (1.78 [1.68 to 1.89]) compared to the 'Normal weight' group. These lifestyle behaviours were clustered, the odds of reporting simultaneous low physical activity, high TV viewing and poor sleep (unhealthy behavioural phenotype) was higher than reporting these behaviours independently, in overweight and obese groups. 'Obese III' adults were almost six times more likely (5.47 [4.96 to 6.05]) to report an unhealthy behavioural phenotype compared to the 'Normal weight' group.

Conclusions: Overweight and obese adults report low levels of physical activity, high TV viewing and poor sleep duration. These behaviours seem to cluster and collectively expose individuals to greater risk of obesity. Multiple lifestyle behaviours should be targeted in future interventions.

Keywords: Physical activity, Sedentary, Sleep, Lifestyle, Obesity

\footnotetext{
*Correspondence: sophie.cassidy@ncl.ac.uk

1 Institute of Cellular Medicine, Faculty of Medical Sciences, Newcastle

University, Newcastle upon Tyne NE2 4HH, UK

Full list of author information is available at the end of the article
} 


\section{Background}

Globally, the proportion of adults with a normal body mass index $(\mathrm{BMI})$ is reducing $[1,2]$ and prediction models indicate that this shift in BMI will continue, so that by 2030 the number of obese adults will have risen by 11 million in the UK alone [3]. Fifty years ago there was no uniformity when measuring obesity, [4] yet the adoption of BMI recommended standards by the World Health Organisation (WHO) [5] meant a standardised definition was created for national surveillance, making it an effective measure for population wide comparisons.

Global and UK strategies for obesity prevention and management promote lifestyle modification, including increased physical activity and healthy nutritional intake, and emphasise their importance before any pharmacological intervention [6-8]. Physical activity is inversely associated with obesity, [9] and improvements in activity levels improve fat oxidation [10] and other determinants of obesity [11]. Across the energy expenditure spectrum, and within a $24 \mathrm{~h}$ period, sedentary behaviour and sleep also influence a person's metabolism, $[12,13]$ and have both been linked to obesity. The direction of association between obesity and sedentary behaviour is not certain, and it remains unclear whether obesity is a cause or consequence of total daily sitting time [14-18]. There is more evidence for television (TV) sitting time and obesity, however other unhealthy behaviours such as snacking are related to TV viewing. Additionally, many obese individuals suffer from sleep apnoea, [19] yet even when controlling for this condition, they have a higher prevalence of short sleep. [20] The strong association between short sleep and increased BMI is well documented, [21] and has been attributed to hormonal imbalances and reductions in energy expenditure [13].

Energy intake is well established as a risk factor for obesity, and diet recommendations form a major part of national guidelines for the prevention and management of weight gain [6]. In this study, energy expenditure was the main focus. As physical activity, sedentary behaviour and sleep are synergistically related to energy expenditure, clustering of these lifestyle behaviours in obesity is expected. Despite this, current policies and interventions to tackle the growing obesity trend often overlook multiple risk behaviours [22]. The UK Biobank provides us with a novel opportunity to simultaneously assess these lifestyle behaviours in a population based sample of UK adults. The UK Biobank is a population-based cohort of 502,664 adults aged 3773 years old, recruited and assessed between 2007 and 2010 [23]. Our aim was to measure physical activity, TV viewing and sleep duration across BMI categories, and to explore clustering between these lifestyle behaviours.

\section{Methods \\ Population and study design}

A cross sectional analysis was conducted on baseline data from the UK Biobank in 2015. Only individuals who had data on physical activity, TV viewing and sleep were included in this analysis $(n=398,984)$ (Fig. 1). Details of UK Biobank methods and procedures have been previously published [23]. All data extracted were de-identified for analysis.

\section{Baseline measurements}

During a verbal interview, disease status was entered and verified by a UK Biobank nurse whereas information on lifestyle behaviours were collected from the touchscreen questionnaire. Physical activity was assessed using six items in the validated Short International Physical Activity Questionnaire (IPAQ) [24]. Time spent in vigorous, moderate, and walking activity was weighted by the energy expended for these categories of activity to

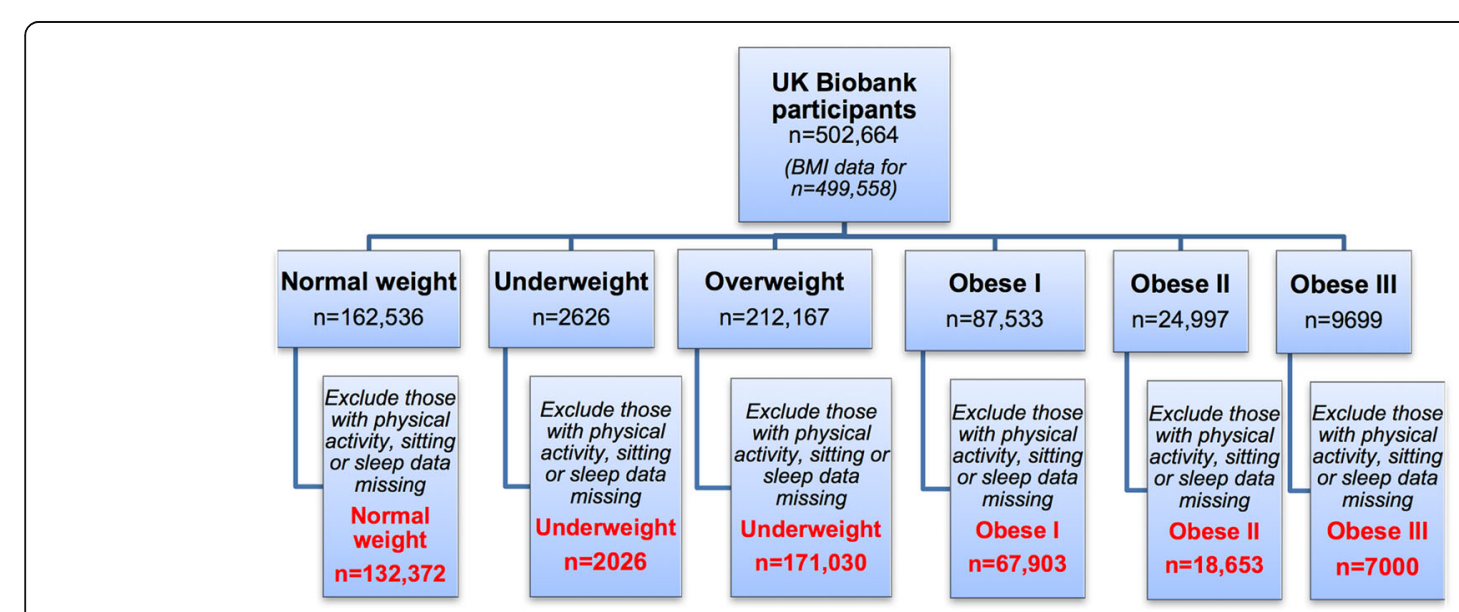

Fig. 1 Flow chart to show how BMl groups were defined (final 4 groups shown in red) 
produce MET.mins/week of physical activity, which is referred to as 'total physical activity'. Data processing rules published by IPAQ were followed [25].

TV viewing [26] was used as a marker of sedentary behaviour. Participants were asked; "In a typical day, how many hours do you spend watching television?" based on previous literature [18]. This was asked twice to those who responded $>8 \mathrm{~h}$, therefore high values were deemed robust. To measure sleep duration, participants were asked "About how many hours sleep do you get in every $24 \mathrm{~h}$ ? (please include naps)". This was asked twice to those who responded $>12 \mathrm{~h}$.

For the other lifestyle behaviours, the touchscreen questionnaire summarised the current/past smoking and alcohol status of the participant and diet intake was reported using the Food Frequency Questionnaire (FFQ) [27]. A short subset of FFQ questions which provided information of commonly eaten food groups and common sources of various nutrients were selected for use in the UK biobank (see [23] for more information). Information on fresh/dried fruit, salad and cooked/raw vegetables were combined to create a binary variable to identify individuals who did and did not meet the UK's current guidelines on fruit and vegetable consumption (five per day) [28]. Participants were asked have you made any major changes to your diet in the last 5 years?' and were also required to select any of the following foods they 'NEVER eat'; eggs, dairy, wheat or sugar.

BMI was calculated from: weight $(\mathrm{kg}) /$ height $(\mathrm{m}){ }^{2}{ }^{2}$ Weight was measured using the Tanita BC-418MA body composition analyser, to the nearest $0.1 \mathrm{~kg}$ and height was measured using a Seca 202 height measure. Bioimpedence (Tanita BC-418MA) was used to measure body fat. Trained staff took these measures and participants were required to remove shoes and heavy outer clothing. Waist circumference was measured at the level of the umbilicus using a Wessex non-stretchable sprung tape measure, which has previously been adopted in large health studies [29]. Participants were asked to adjust clothing for an accurate measure, and all staff were trained in taking these measures.

\section{Data analysis}

BMI groups were defined based on WHO recommended cut points [30] which are; $<18.5 \mathrm{~kg} / \mathrm{m}^{2}$ (underweight), $18.5-24.99 \mathrm{~kg} / \mathrm{m}^{2}$ (normal weight), $25-29.99 \mathrm{~kg} / \mathrm{m}^{2}$ (overweight), $30-34.99 \mathrm{~kg} / \mathrm{m}^{2}$ (obese I), $35-39.99 \mathrm{~kg} / \mathrm{m}^{2}$ (Obese II) and $\geq 40 \mathrm{~kg} / \mathrm{m}^{2}$ (Obese III). Individuals with missing data on either total physical activity, sitting time or sleep were excluded $(n=100,574)$. Additional file 1 shows the socio-demographics of missing cases, which were similar to the main cohort, but there was a greater proportion of obese individuals aged 60-70 years and there was a lower proportion of males across all groups.
Total physical activity, vigorous, moderate and walking mins and TV viewing time were categorised into 4 groups. These groups were based on the quartile demarcators for the 'Normal weight' BMI adults, within each variable. Total physical activity groups were labelled as 'low physical activity' (lowest quartile: $\leq 967.5$ MET. mins/wk) and 'high physical activity' (highest quartile: $>3786$ MET.mins/wk) and TV viewing was labelled as 'low TV viewing' (lowest quartile: $\leq 1$ hour/day) and 'high TV viewing' (highest quartile: $>3$ hour/day). As the relationship between obesity and sleep duration is not a linear, sleep duration was split using pre-defined thresholds $(<7,7-8,>8 \mathrm{~h} / \mathrm{night})$ from the literature [20,31]. Sleep duration was labelled as 'poor sleep' ( $<7$ or $>8 \mathrm{~h} /$ night) and 'good sleep' (7-8 h/night).

\section{Statistical analysis}

All data analyses were performed using SPSS, version 21.0 (IBM, Armonk, NY, USA). Due to the large sample size, Pearson's chi squared deemed any small difference in group proportions as significant, therefore these results are not reported. Physical activity, TV viewing and sleep duration were statistically analysed across BMI groups. Binary logistic regression was used to determine the odds of reporting low physical activity, high TV viewing and poor sleep duration separately, according to BMI group. We also looked at the clustering of these behaviours. Participants were categorised as having an 'unhealthy phenotype' if they were categorised in all of the following groups; low total physical activity, high $\mathrm{TV}$ viewing and poor sleep duration. As BMI isn't a direct measure of obesity, the National Institute for Health and Care Excellence (NICE) recommended combining BMI in conjunction with waist circumference [1]. Due to the spread of waist circumference in 'overweight' and 'obese I' groups, we further classified these groups by waist circumference and performed the above analysis (see Additional file 1). Adjusted odds ratios, with $95 \%$ confidence intervals were reported. All logistic regression models were adjusted for: age (reference $=40-50$ "), gender (reference $="$ Female"), Townsend Deprivation Index (reference="least deprived"), Ethnicity (reference="White/British"), Alcohol (reference="never"), Smoking (reference="Never"), Meets fruit/veg guidelines (reference="Yes"), Sleep Apnoea (reference="No"), Cardio-metabolic disease (reference $=$ "No"). Cardiometabolic disease and sleep apnoea were identified as confounders because cardio-metabolic disease and BMI are strongly associated, and obesity results in sleep apnoea which disturbs sleep. Of the 398,984 cohort, data was missing for; Townsend Deprivation Index (0.1\%), Ethnicity (0.3\%), and fruit and vegetable guidelines $(0.015 \%)$ therefore these cases were excluded from the logistic regression models. 


\section{Results}

Of the 398,984 UK Biobank participants who had data on physical activity, TV viewing and sleep; $33 \%(n=132,372)$ were 'normal weight', $0.5 \%(n=2026)$ 'Underweight', 43\% $(n=171,030)$ 'Overweight', 17\% $(n=67,903)$ 'Obese I', $5 \%$ $(n=18,653)$ 'Obese II', and $2 \%(n=7000)$ 'Obese III' (Fig. 1). Table 1 displays the socio-demographics of BMI groups.

Total weekly physical activity decreased across BMI groups with $25 \%$ of 'Normal weight' adults reaching the high quartile of physical activity ( $>3786$ METs.min.wk) compared to $12.7 \%$ of 'Obese III' adults (Table 2). Fifteen per cent of 'Normal weight' adults did not meet the UK's physical activity recommendations, which rose across BMI groups to $38.2 \%$ in 'Obese III' adults. The proportion of adults reporting high TV viewing increased across BMI groups ('Normal weight', $19.2 \%$ vs. 'Overweight', $28.3 \%$ vs. 'Obese III', 47.1\%) so that almost half of 'Obese III' adults reported TV viewing for greater than $>3 \mathrm{~h}$ per day (Table 2). Good sleep duration declined across BMI groups with $72 \%$ of 'Normal weight' adults reporting $7-8$ h sleep per night and only $54.5 \%$ of 'Obese III' adults reporting similar levels (Table 2). Figure 2 is a visual representation of the differences in these lifestyle behaviours across BMI groups.

Logistic regression models demonstrated that increased BMI is associated with a greater likelihood of reporting low physical activity, high TV viewing and

Table 1 Socio-demographics, anthropometry and disease status within each BMI group $(n=398,984)$

\begin{tabular}{|c|c|c|c|c|c|c|}
\hline & \multicolumn{6}{|c|}{ \% Within each disease group } \\
\hline & $\begin{array}{l}\text { Under weight } \\
<18.5 \\
(n=2026)\end{array}$ & $\begin{array}{l}\text { Normal weight } \\
18.5-24.99 \\
(n=132,372)\end{array}$ & $\begin{array}{l}\text { Over weight } \\
25-29.99 \\
(n=171,030)\end{array}$ & $\begin{array}{l}\text { Obese I } \\
30-34.99 \\
(n=67,903)\end{array}$ & $\begin{array}{l}\text { Obese II 35-39.99 } \\
(n=18,653)\end{array}$ & $\begin{array}{l}\text { Obese } I I I \geq 40 \\
(n=7000)\end{array}$ \\
\hline$\%$ Male & 20.9 & 36.3 & 55.2 & 54.1 & 43.2 & 34.3 \\
\hline Age $(n)$ & 2026 & 132,372 & 171,030 & 67,903 & 18,653 & 7000 \\
\hline $40-49$ & 27.7 & 28.1 & 22.6 & 21.6 & 23.1 & 26.9 \\
\hline $50-59$ & 36.6 & 33.7 & 32.4 & 32.2 & 36.0 & 39.2 \\
\hline $60-70$ & 35.7 & 38.2 & 45.1 & 44.3 & 40.9 & 33.9 \\
\hline Tanita body fat $\%$ (mean \pm SD) & $18.6 \pm 5.4$ & $26.7 \pm 7.1$ & $30.8 \pm 7.3$ & $36.0 \pm 7.2$ & $41.3 \pm 6.8$ & $46.3 \pm 6.2$ \\
\hline Waist circumference groups (MALES) (n) & 424 & 48,049 & 94,322 & 36,730 & 8060 & 2407 \\
\hline$<94 \mathrm{~cm}$ (low risk) & 99.8 & 90.1 & 35.6 & 1.8 & 0.0 & 0.1 \\
\hline 94-102 cm (high risk) & 0.2 & 9.7 & 49.9 & 24.8 & 1.3 & 0.1 \\
\hline >102 cm (very high risk) & 0.0 & 0.2 & 14.5 & 73.4 & 98.7 & 99.8 \\
\hline Waist circumference groups (FEMALES) (n) & 1602 & 84,302 & 76,688 & 31,151 & 10,590 & 4581 \\
\hline$<80 \mathrm{~cm}$ (low risk) & 99.5 & 78.6 & 20.2 & 0.8 & 0.0 & 0.0 \\
\hline 80-88 cm (high risk) & 0.2 & 19.4 & 48.7 & 14.2 & 1.1 & 0.1 \\
\hline$>88$ cm (very high risk) & 0.2 & 2.0 & 31.1 & 85.0 & 98.8 & 99.9 \\
\hline Cardio-metabolic disease & 35.8 & 37.2 & 56.1 & 71.8 & 81.0 & 86.8 \\
\hline Sleep apnoea (n) & $0.0(1)$ & $0.1(76)$ & $0.2(345)$ & $0.6(404)$ & $1.4(267)$ & $2.7(188)$ \\
\hline Townsend deprivation quintile ( $n$ ) & 2023 & 132,214 & 170,825 & 67,811 & 18,622 & 6986 \\
\hline 1 (least deprived) & 17.4 & 22.0 & 21.4 & 18.6 & 15.0 & 12.0 \\
\hline 2 & 17.3 & 20.9 & 21.0 & 19.3 & 17.2 & 14.0 \\
\hline 3 & 18.1 & 20.2 & 20.5 & 19.8 & 18.9 & 18.0 \\
\hline 4 & 20.8 & 19.6 & 19.7 & 20.7 & 21.9 & 22.4 \\
\hline 5 (most deprived) & 26.4 & 17.3 & 17.4 & 21.7 & 27.0 & 33.7 \\
\hline Ethnicity $(n)$ & 2016 & 132,020 & 170,546 & 67,672 & 18,594 & 6970 \\
\hline White/British & 93.5 & 95.3 & 95.0 & 94.5 & 94.2 & 93.3 \\
\hline Mixed & 1.0 & 0.6 & 0.5 & 0.6 & 0.6 & 0.8 \\
\hline Asian & 2.3 & 1.8 & 1.9 & 1.7 & 1.3 & 1.1 \\
\hline Black African & 0.4 & 0.8 & 1.5 & 2.2 & 2.9 & 3.7 \\
\hline Chinese & 1.2 & 0.6 & 0.2 & 0.1 & 0.0 & 0.0 \\
\hline Other & 1.5 & 0.8 & 0.8 & 0.9 & 1.0 & 1.0 \\
\hline
\end{tabular}


Table 2 Lifestyle characteristics including physical activity, TV viewing, sleep, smoking, alcohol and diet, within each BMI group $(n=398,984)$

\begin{tabular}{|c|c|c|c|c|c|c|}
\hline & \multicolumn{6}{|c|}{$\%$ Within each disease group } \\
\hline & $\begin{array}{l}\text { Under weight } \\
<18.5 \\
(n=2026)\end{array}$ & $\begin{array}{l}\text { Normal weight } \\
18.5-24.99 \\
(n=132,372)\end{array}$ & $\begin{array}{l}\text { Over weight } \\
25-29.99 \\
(n=171,030)\end{array}$ & $\begin{array}{l}\text { Obese I } \\
30-34.99 \\
(n=67,903) \\
\end{array}$ & $\begin{array}{l}\text { Obese II 35-39.99 } \\
(n=18,653)\end{array}$ & $\begin{array}{l}\text { Obese } I I I \geq 40 \\
(n=7000)\end{array}$ \\
\hline \multicolumn{7}{|l|}{ Physical Activity } \\
\hline Total Physical activity ${ }^{\text {a }}$ (MET.mins/wk) & 2026 & 132,372 & 171,030 & 67,903 & 18,653 & 7000 \\
\hline$\leq 967.5$ (Low physical activity) & 28.0 & 25.0 & 28.9 & 35.6 & 42.9 & 52.5 \\
\hline$>967.5-1989.5$ & 23.9 & 25.0 & 24.8 & 23.4 & 22.8 & 20.7 \\
\hline$>1989.5-3786$ & 22.2 & 25.0 & 22.9 & 20.1 & 17.4 & 14.2 \\
\hline >3786 (High physical activity) & 25.9 & 25.0 & 23.4 & 20.8 & 16.9 & 12.7 \\
\hline Walking $^{a}$ (mins/day) & 2026 & 132,372 & 171,030 & 67,903 & 18,653 & 7000 \\
\hline $0-20$ & 29.2 & 30.6 & 32.4 & 35.9 & 40.4 & 48.0 \\
\hline $21-30$ & 19.9 & 21.1 & 20.8 & 19.8 & 19.3 & 18.1 \\
\hline $31-60$ & 27.9 & 27.4 & 26.2 & 24.3 & 22.3 & 20.0 \\
\hline $61-180$ & 23.0 & 21.0 & 20.6 & 20.0 & 18.0 & 13.9 \\
\hline Moderate activity $^{a}$ (mins/day) & 2026 & 132,372 & 171,030 & 67,903 & 18,653 & 7000 \\
\hline $0-15$ & 25.2 & 20.1 & 23.0 & 28.4 & 33.9 & 42.1 \\
\hline $16-30$ & 30.3 & 33.4 & 32.6 & 31.1 & 31.1 & 28.7 \\
\hline $31-60$ & 23.6 & 25.9 & 24.2 & 21.8 & 19.1 & 17.1 \\
\hline $61-180$ & 20.9 & 20.6 & 20.2 & 18.7 & 15.8 & 12.2 \\
\hline Vigorous activity ${ }^{a}$ (mins/day) & 2026 & 132,372 & 171,030 & 67,903 & 18,653 & 7000 \\
\hline 0 & 48.6 & 35.5 & 39.5 & 47.6 & 56.2 & 64.0 \\
\hline $1-20$ & 17.9 & 20.8 & 20.4 & 19.2 & 17.4 & 15.0 \\
\hline $21-45$ & 16.9 & 21.1 & 19.2 & 16.2 & 13.3 & 11.6 \\
\hline $46-180$ & 16.5 & 22.6 & 20.8 & 17.0 & 13.2 & 9.4 \\
\hline $\begin{array}{l}\text { Meets UK government physical activity } \\
\text { guidelines }{ }^{\mathrm{b}}\end{array}$ & 2026 & 132,372 & 171,030 & 67,903 & 18,653 & 7000 \\
\hline NO & 16.4 & 14.6 & 17.8 & 23.1 & 29.2 & 38.2 \\
\hline \multicolumn{7}{|l|}{ TV viewing } \\
\hline TV viewing ${ }^{a}$ (h/day) & 2026 & 132,372 & 171,030 & 67,903 & 18,653 & 7000 \\
\hline$\leq 1$ (Low TV viewing) & 35.0 & 30.0 & 19.6 & 14.1 & 11.2 & 9.9 \\
\hline$>1-2$ & 28.3 & 29.9 & 27.6 & 24.5 & 21.7 & 19.6 \\
\hline$>2-3$ & 17.6 & 20.9 & 24.5 & 25.3 & 24.6 & 23.4 \\
\hline$>3$ (High TV viewing) & 19.1 & 19.2 & 28.3 & 36.1 & 42.5 & 47.1 \\
\hline \multicolumn{7}{|l|}{ Sleep } \\
\hline Sleep duration ${ }^{c}$ (h/night) & 2026 & 132,372 & 171,030 & 67,903 & 18,653 & 7000 \\
\hline$<7,>8$ (Poor sleep) & 33.1 & 28.1 & 30.9 & 36.2 & 40.8 & 45.4 \\
\hline 7-8 (Good sleep) & 66.9 & 72.0 & 69.1 & 63.8 & 59.3 & 54.5 \\
\hline \multicolumn{7}{|l|}{ Behavioural Phenotype } \\
\hline $\begin{array}{l}\text { Unhealthy (low physical activity, high TV } \\
\text { viewing and poor sleep duration) }\end{array}$ & $\begin{array}{l}2.7 \% \\
(n=72)\end{array}$ & $\begin{array}{l}1.6 \% \\
(n=2639)\end{array}$ & $\begin{array}{l}2.6 \% \\
(n=5486)\end{array}$ & $\begin{array}{l}4.4 \% \\
(n=3880)\end{array}$ & $\begin{array}{l}6.6 \% \\
(n=1644)\end{array}$ & $\begin{array}{l}9.9 \% \\
(n=956)\end{array}$ \\
\hline \multicolumn{7}{|l|}{ Other Lifestyle Behaviours } \\
\hline Alcohol & 2026 & 132,372 & 171,030 & 67,903 & 18,653 & 7000 \\
\hline Never & 7.7 & 3.7 & 3.6 & 4.6 & 5.7 & 7.7 \\
\hline Previous & 6.8 & 3.1 & 3.1 & 3.9 & 5.0 & 7.5 \\
\hline Current & 85.3 & 93.1 & 93.2 & 91.4 & 89.2 & 84.7 \\
\hline
\end{tabular}


Table 2 Lifestyle characteristics including physical activity, TV viewing, sleep, smoking, alcohol and diet, within each BMI group $(n=398,984)$ (Continued)

\begin{tabular}{|c|c|c|c|c|c|c|}
\hline Smoking & 2026 & 132,372 & 171,030 & 67,903 & 18,653 & 7000 \\
\hline Never & 57.3 & 59.2 & 53.3 & 50.3 & 50.5 & 52.5 \\
\hline Previous & 20.9 & 29.8 & 36.4 & 39.7 & 39.8 & 37.9 \\
\hline Current & 21.6 & 10.7 & 10.0 & 9.7 & 9.2 & 9.2 \\
\hline \multicolumn{7}{|l|}{ Diet } \\
\hline Dietary change in past 5 years & 2023 & 132,261 & 170,862 & 67,799 & 18,600 & 6973 \\
\hline YES & 29.3 & 32.1 & 39.0 & 46.9 & 54.5 & 59.5 \\
\hline Meets fruit/veg guidelines & 2001 & 130,905 & 168,617 & 66,812 & 18,302 & 6887 \\
\hline YES & 32.7 & 32.1 & 30.4 & 30.3 & 31.7 & 32.3 \\
\hline "Never eat" & 2024 & 132,151 & 170,699 & 67,757 & 18,602 & 6970 \\
\hline $\begin{array}{l}\text { Never eat sugar or foods/drinks } \\
\text { containing sugar }\end{array}$ & 13.1 & 15.5 & 18.7 & 21.6 & 24.2 & 25.8 \\
\hline
\end{tabular}

${ }^{a}$ For physical activity and TV sitting time, quartiles were calculated from the 'No Disease' group so that their demarcators could be applied to disease group

bUK Government recommendations of $150 \mathrm{mins}$ of moderate or $75 \mathrm{mins}$ of vigorous activity per week. Walking was considered 'moderate' activity for this calculation

'Physiological thresholds used rather than quartiles because the shape of the risk relationship is a U shape (not linear like Physical activity and TV viewing)

poor sleep duration (Table 3). Indeed, 'Obese III' adults were 3 times more likely to report low physical activity (OR [95\% CI] 3.13 [2.95-3.32]), 3 times more likely to report high TV viewing (3.26 [3.07-3.47]), and almost twice as likely to report poor sleep duration (1.78 [1.68-1.89]) than 'Normal' weight adults. The odds of reporting all three unhealthy behaviours together was higher than reporting one of these lifestyle behaviours individually. Relative to 'Normal' weight adults, 'Obese III' adults were 5 times (5.47 [4.96 to 6.05]) more likely to report an 'unhealthy phenotype' when controlling for confounders (Table 3). The shift in this unhealthy phenotype across BMI groups is visualised in Fig. 3 which shows the movement from healthy behaviours (green/right) to unhealthy behaviours (red/left).

The odds of reporting unhealthy lifestyle behaviours increased according to waist circumference risk in the 'Overweight' and 'Obese I' groups. Furthermore, 'Overweight' individuals with a very high risk waist $\mathrm{cm}$ (Male $>102 \mathrm{~cm}$ and Female $>88 \mathrm{~cm}$ ) were more likely to report low physical activity levels and the likelihood of reporting an 'unhealthy phenotype' was similar to 'Obese' adults with a low risk waist circumference (Male <94 and Female <80) (Additional file 1).

\section{Discussion}

This is the largest UK population study to simultaneously assess physical activity, TV viewing and sleep duration across BMI groups. The results from the study indicate that these lifestyle behaviours cluster. Indeed obese adults are two to five times more likely to report an 'unhealthy phenotype', consisting of low physical activity, high TV viewing and poor sleep duration compared to normal weight adults. Physical activity, sedentary behaviour and poor sleep remain significant unaddressed risk factors in those who are overweight and obese.

Overweight and obese adults reported lower physical activity levels. Those with a BMI of $\geq 35$, were two to three times more likely to report low levels of physical activity compared to normal weight adults. Global recommendations state adults should be performing at least 150 mins moderate or 75 mins vigorous physical activity weekly, but evidence states that this should be increased to $300 \mathrm{mins} /$ week for additional health benefits [7, 32] Data from the UK Biobank showed that almost $40 \%$ of adults with a BMI of $\geq 40$ were not meeting the basic recommendations. A survey in England demonstrated that only $5 \%$ of adults could recall physical activity recommendations which was substantially lower than the $78 \%$ who could recall fruit and vegetable recommendations [33], highlighting a potential knowledge gap surrounding physical activity and health. There was a strong association between physical activity and waist $\mathrm{cm}$, indeed overweight adults with a 'very high risk waist $\mathrm{cm}$ ' had higher odds of reporting low physical activity, compared to obese I adults with a lower waist $\mathrm{cm}$. These results are not surprising, considering that physical activity is strongly linked with visceral fat deposition. Although it's clear that physical inactivity is a problem in obesity, a bi-directional relationship between physical activity and obesity is likely to exist [34].

$\mathrm{TV}$ viewing increased across BMI groups so that obese adults were 2-3 times more likely to report high levels compared to normal weight individuals. A number of cross sectional studies have demonstrated associations between sedentary behaviour and obesity, [17, 18, 35] however prospective data indicate bidirectional associations, 


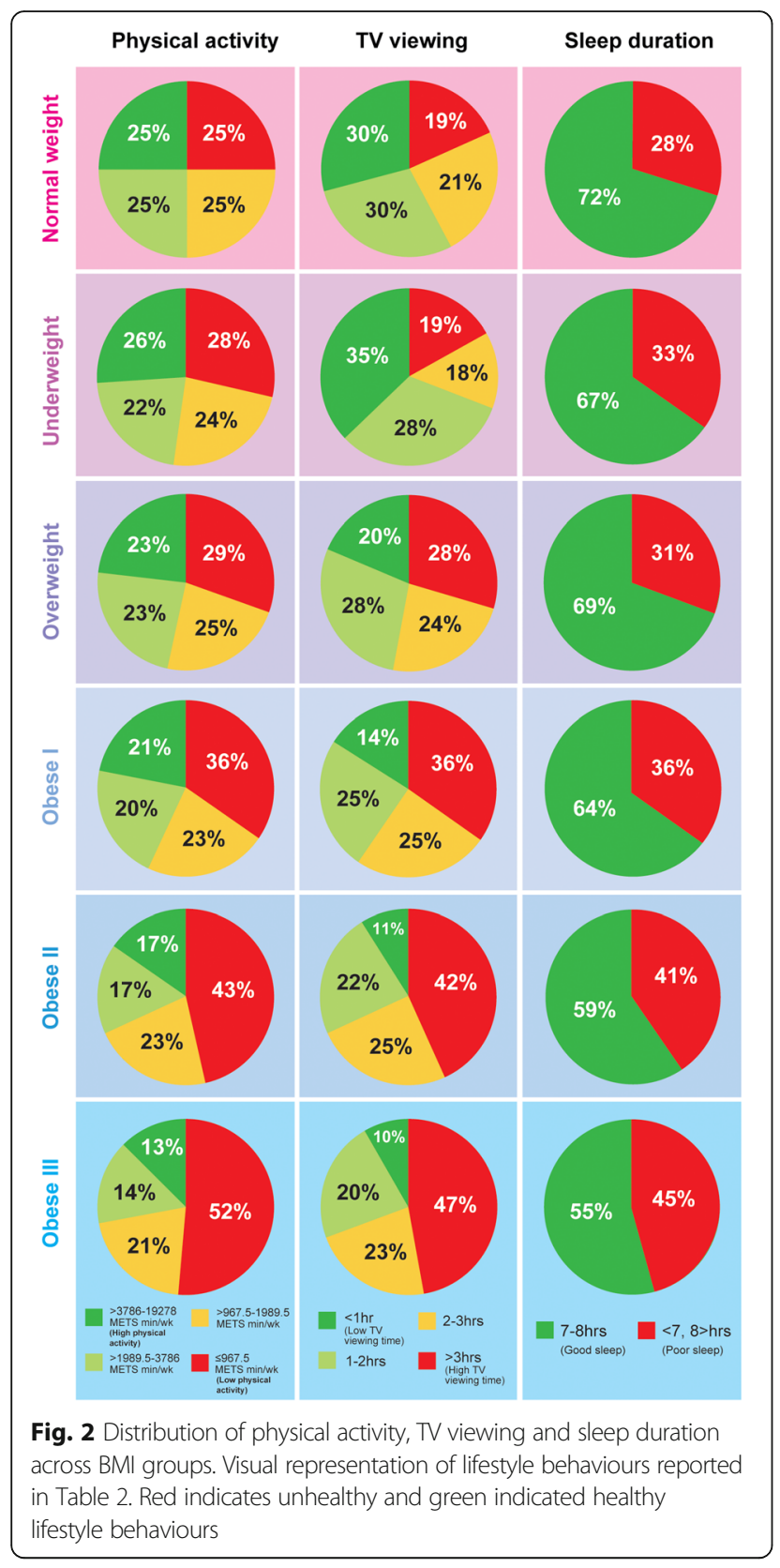

whereby obesity leads to high sedentary time and vice versa $[14,15]$. Unlike the strong associations between sedentary behaviour and cardio-metabolic risk, the relationship with obesity is less clear [36]. Whether high TV sitting time amongst obese individuals in the UK biobank is simply a proxy for low total daily energy expenditure, or whether it represents an independent risk for obesity remains to be determined, and more clinical trials are warranted. The most recent UK national guidelines for obesity briefly state that adults should limit TV viewing to $2 \mathrm{~h}$ per day [6] but results from this cohort indicate that more than half of overweight and obese adults exceed this limit on a daily basis. No further guidance on reducing sedentary behaviour is provided within current national and global guidelines. In 2014, the UK did produce the first ever UK strategy to embed physical activity and reduce sedentary behaviour into the fabric of daily life, [37] however, this was just a 'framework for action' rather than providing definite solutions to tackle sedentariness.

Sleep as a modifiable lifestyle behaviour in obesity prevention and management is rarely mentioned, despite data from this study showing a decline in good sleep (7-8 h per night) across BMI groups. Even when controlling for sleep apnoea, overweight and obese individuals were more likely to report short $(<7 \mathrm{~h})$ or long ( $>8 \mathrm{~h}$ ) sleep duration. When sleep was measured objectively, a previous study also identified greater obesity risks with short sleep $(<5 \mathrm{~h})$ and demonstrated a ' $U$ ' shaped relationship with body fat [20]. Short sleep has been linked to metabolic dysregulation [38] and long sleep will clearly impact on the potential to be physically active during wakefulness. Nevertheless, the causal relationship between sleep and obesity have yet to be identified and a bidirectional relationship may exist, but these findings suggest sleep could be important in obesity pathogenesis.

These lifestyle behaviours seem to cluster, indeed the likelihood of reporting all three unhealthy behaviours (low physical activity, high TV viewing and poor sleep duration) was higher than reporting individual unhealthy behaviours in each BMI category. 'Obese I' adults were

Table 3 Odds [95\% Cl] of reporting unhealthy lifestyle behaviours separately and combined, across BMl groups

\begin{tabular}{lllll}
\hline & Low physical activity & High TV viewing & Poor sleep & $\begin{array}{l}\text { Low physical } \\
\text { activity + High } \\
\text { sitting + Poor sleep }\end{array}$ \\
\hline$<18.5$ (underweight) & $1.00[0.86-1.16]$ & $0.91[0.77-1.07]$ & $1.17[1.02-1.35]$ & $1.40[0.96-2.02]$ \\
$18.5-24.9$ (normal weight) & 1.00 & 1.00 & 1.00 & 1.00 \\
25-29.9 (overweight) & $1.23[1.20-1.26]$ & $1.52[1.48-1.55]$ & $1.09[1.07-1.12]$ & $1.44[1.35-1.54]$ \\
$30-34.9$ (obese I) & $1.66[1.61-1.71]$ & $2.06[2.00-2.12]$ & $1.31[1.27-1.34]$ & $2.38[2.22-2.55]$ \\
$35-39.9$ (obese II) & $2.21[2.12-2.30]$ & $2.69[2.58-2.80]$ & $1.50[1.44-1.56]$ & $3.49[3.21-3.79]$ \\
$>40$ (obese III) & $3.13[2.95-3.32]$ & $3.26[3.07-3.47]$ & $1.78[1.68-1.89]$ & $5.47[4.96-6.05]$ \\
\hline
\end{tabular}

All Models adjusted for age, gender, socio-demographic (Townsend deprivation and ethnicity), smoking, alcohol, meets fruit + vegetable guidelines, cardio-metabolic disease and sleep apnoea 


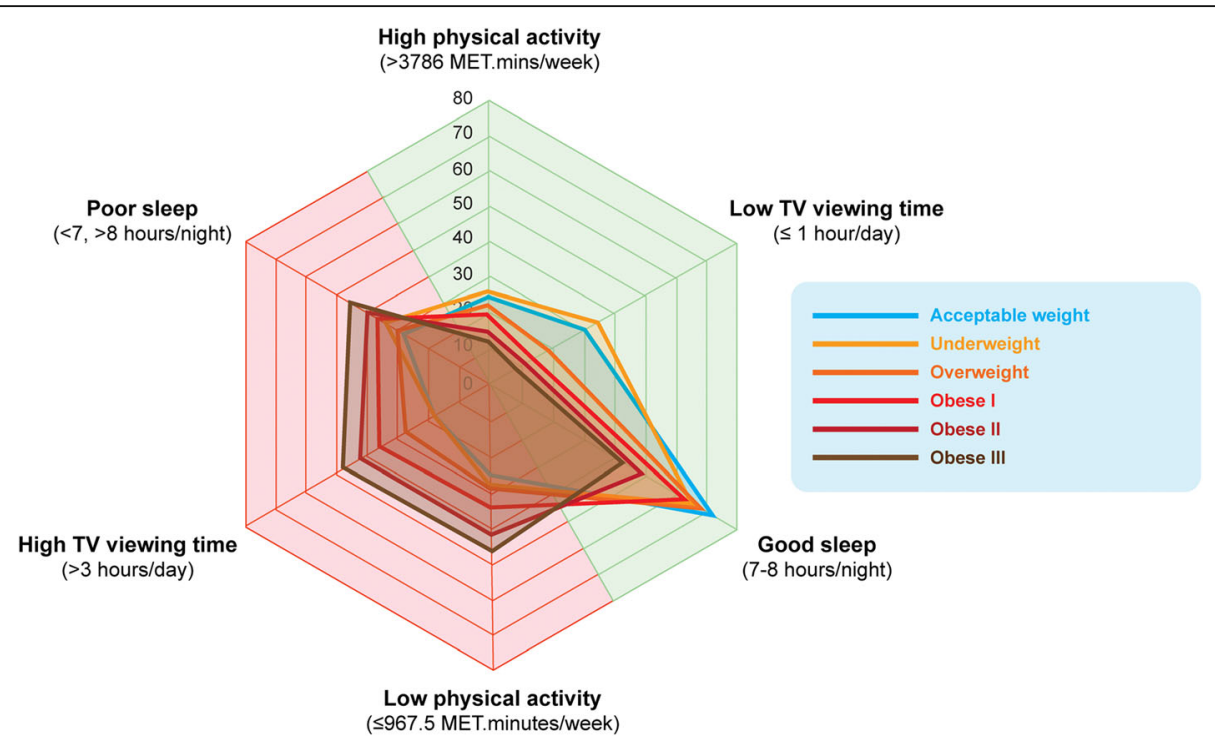

Fig. 3 Radar chart showing the proportion of adults in each group who were categorised as either 'high' or 'low' for total physical activity or TV viewing, or 'good' or 'poor' for sleep duration. Green side indicates healthy lifestyle behaviours whereas red side indicates unhealthy behaviours. There is a shift leftwards towards unhealthy behaviours with an increase in BMI

two times more likely and 'Obese III' were five times more likely to report an unhealthy behavioural phenotype compared to 'normal weight 'individuals. This indicates that the combination of unhealthy physical activity, TV viewing and sleep duration may expose individuals to greater obesity risk. It is possible that all three behaviours are interdependent on their influence upon energy balance and subsequent obesity risk. Muscular contraction during physical activity expends energy. Conversely, high sedentary behaviour decreases the daily work performed by large skeletal muscles in the back, legs and trunk large thereby reducing energy expenditure [12]. Energy intake has been linked to sleep through appetite control. Indeed sleep debt elevates ghrelin and reduces leptin which explains the strong link between sleep deprivation, raised energy intake and weight gain [13]. Collectively therefore, low physical activity, high sedentary behavior and poor sleep are likely to have a profound influence upon energy balance and weight gain. It is important to note that time spent in physical activity, sedentary behaviours and sleep are codependent, with a finite amount of time during the day, each behavior will influence the other [39].

This clustering of lifestyle behaviours suggests that to tackle the rising obesity trend, interventions solely targeting single lifestyle behaviours may be inadequate. To date, most intervention studies have focused on changing single lifestyle behaviours [22] but targeting multiple behaviours should be the focus of future strategies. The UK's national clinical guidelines recently mentioned the possibility of lifestyle clustering and that unhealthy individuals may follow a range of unhealthy lifestyle behaviours which add to weight gain [6]. Our results confirm this hypothesis that overweight and obese individuals display a number of unhealthy behaviours which should all be prioritised in future interventions.

Dietary data indicate that overweight and obese UK adults were more likely to have changed their diet in the previous 5 years, consume a similar amount of fruit/vegetables, and less likely to eat sugar, compared to normal weight individuals. These behaviours are in line with existing guidelines $[6,8]$ however the results need to interpreted with caution. Self-report has major limitations in obese adults, [40] with significant underestimation of calorie intake. Although overweight and obese adults report making dietary changes, we cannot comment on the quality of these dietary changes. Over recent decades, food has become more varied, less expensive and more palatable, therefore dietary advice has been at the centre of lifestyle recommendations for tackling obesity. Despite the obvious limitations of this data, the results indicate that UK adults are at least aware of the importance of diet and emphasis should additionally be placed upon other lifestyle behaviours.

\section{Limitations}

Strengths of the study are the large sample size allowing greater precision and resolution of associations, detailed measurements as well as the population based design. However, the response rate for the UK Biobank was only $5 \%$ which raises the strong possibility of selection bias and therefore reduced generalisability of results as this sample is unlikely to be a true representative of the general population. The cross sectional nature of this study means we cannot comment on the direction of causality. 
Additionally, lifestyle behaviours were self-report which is known to lead to over-reporting with physical activity data [41]. That being said, all questionnaires used in the study were validated and more easily adopted for population wide studies compared to objective measures. Using TV viewing as a proxy measure of sedentary behaviour does not take into account the fact that TV viewing and weight outcomes may be caused by several factors such as snacking during TV, and being prompted to eat by TV. Nonetheless, TV sitting time is a commonly used measure of sedentary behaviour in epidemiological studies and has good test-retest reliability [42]. Calculation of total daily sitting time, which is a more complete measure, was not possible from the UK Biobank questionnaire used.

\section{Conclusions}

In summary, the present data indicate that overweight and obese adults report low levels of physical activity, high TV viewing and poor sleep duration. These lifestyle behaviours seem to cluster and may collectively expose individuals to greater risk of obesity. Those who are obese are two to five times more likely to display an 'unhealthy phenotype' compared to normal weight adults. Current guidelines for obesity recommend pharmacological intervention to begin only once lifestyle have been implemented. Despite this emphasis on lifestyle, the results from the UK Biobank suggest that physical activity, sedentary behaviour and sleep remain significant unaddressed risk factors for obesity. This highlights the need for more effective strategies, which target multiple lifestyle behaviours, to prevent the rising tide of obesity.

\section{Additional file}

Additional file 1: The socio-demographics of the missing cases and logistic regression analysis with waist circumference. (DOCX $27 \mathrm{~kb}$ )

\section{Abbreviations}

BMI: Body Mass Index; IPAQ: International Physical Activity Questionnaire; NICE: National Institute for Health and Care Excellence; TV: Television; WHO: World Health Organisation

\section{Acknowledgements}

This research was conducted using the UK Biobank resource. The authors would like to thank the UK Biobank participants and investigators for making this study possible. We would also like to acknowledge the Newcastle University Centre for Ageing and Vitality sponsored by the BBSRC, EPSRC, ESRC and MRC. We would like to thanks Louise Taylor for her assistance with the design of Figures.

\section{Funding}

The UK Biobank was established by the Wellcome Trust medical charity, Medical Research Council, Department of Health, Scottish Government and the Northwest Regional Development Agency. It has also received funding from the Welsh Assembly Government and the British Heart Foundation. The analyses were supported by the Newcastle University Centre for Ageing and Vitality sponsored by the BBSRC, EPSRC, ESRC and MRC; JYC was supported by a Postdoctoral Fellowship (number 100567) from the National Heart Foundation of Australia; MIT was supported by a Senior Research Fellowship from the National Institute for Health Research (NIHR-SRF-04-017).

\section{Availability of data and materials}

The data that support the findings of this study are available from UK Biobank but restrictions apply to the availability of these data, which were used under license for the current study, and so are not publicly available. Data are however available from the authors upon reasonable request and with permission of UK Biobank.

\section{Authors' contributions}

SC, JYC and AB performed data analysis and epidemiology expertise was provided by JYC and AB. Data interpretation and statistical input was provided by JYC, MC, AB and MIT. SC and MIT wrote the first draft of the paper and all other authors contributed to successive drafts. All authors read and approved the final report.

\section{Competing interests}

The authors declare that they have no competing interests.

\section{Consent for publication}

Not applicable.

\section{Ethics approval and consent to participate}

The UK Biobank study was approved by the North West Multi-centre Research Ethics Committee, the England and Wales Patient Information Advisory Group, and the Scottish Community Health Index Advisory Group and participant written informed consent was obtained prior to data collection.

\section{Publisher's Note}

Springer Nature remains neutral with regard to jurisdictional claims in published maps and institutional affiliations.

\section{Author details}

${ }^{1}$ Institute of Cellular Medicine, Faculty of Medical Sciences, Newcastle University, Newcastle upon Tyne NE2 4HH, UK. ${ }^{2}$ Prevention Research Collaboration, Sydney School of Public Health, Charles Perkins Centre D17, Level 6 The Hub, University of Sydney, Sydney, NSW 2006, Australia. ${ }^{3}$ Institute of Neuroscience, Faculty of Medical Sciences, Newcastle University, Newcastle upon Tyne NE2 4HH, UK.

Received: 7 December 2016 Accepted: 19 April 2017

Published online: 28 April 2017

\section{References}

1. Health and Social Care Information Centre. Statistics on Obesity, Physical Activity and Diet-England 2015. 2015

2. Ng M, Fleming T, Robinson M, Thomson B, Graetz N, Margono C, Mullany EC, Biryukov S, Abbafati C, Abera SF, Abraham JP, Abu-Rmeileh NME, Achoki T, AlBuhairan FS, Alemu ZA, Alfonso R, Ali MK, Ali R, Guzman NA, Ammar W, Anwari P, Banerjee A, Barquera S, Basu S, Bennett DA, Bhutta Z, Blore J, Cabral N, Nonato IC, Chang J-C, et al. Global, regional, and national prevalence of overweight and obesity in children and adults during 19802013: a systematic analysis for the Global Burden of Disease Study 2013. Lancet. 2014;384:766-81.

3. Wang YC, McPherson K, Marsh T, Gortmaker SL, Brown M. Health and economic burden of the projected obesity trends in the USA and the UK. Lancet. 2011;378:815-25.

4. Bouchard C. How much progress have we made over the last few decades? Int J Obes (Lond). 2008;32 Suppl 7:S2-7.

5. World Health Organisation: Obesity- Preventing and Managing the Global Epidemic. Report of a WHO Consultation on Obesity, Held in Geneva, 1997. Geneva: World Health Organisation. 1997. http://www.who.int/nutrition/ publications/obesity/WHO_TRS_894/en/.

6. NICE. Preventing Excess Weight Gain. 2015.

7. NICE. Obesity: Identification, Assessment and Management. 2014.

8. Swinburn B, Caterson I, Seidell J, James W. Diet, nutrition and the prevention of excess weight gain and obesity. Public Health Nutr. 2003;7:123-46.

9. Lahti-Koski M, Pietinen P, Heliövaara M, Vartiainen E. Associations of body mass index and obesity with physical activity, food choices, alcohol intake, and smoking in the 1982-1997 FINRISK Studies. Am J Clin Nutr. 2002;75:809-17.

10. Trenell M, Hollingsworth KGH, Lim EL, Taylor R: Increased Daily Walking Improves Lipid Oxidation Without Changes in Mitochondrial Function in Type 2 Diabetes. Diabetes Care 2008;31(8):1644-1649. 
11. Ilanne-Parikka P, Laaksonen DE, Eriksson JG, Lakka TA, Lindstr J, Peltonen M, Aunola S, Keinánen-Kiukaanniemi S, Uusitupa M, Tuomilehto J. Leisure-time physical activity and the metabolic syndrome in the Finnish diabetes prevention study. Diabetes Care. 2010;33:1610-7.

12. Hamilton MT, Hamilton DG, Zderic TW: Role of Low Energy Expenditure and Sitting in Obesity, Metabolic Syndrome, Type 2 Diabetes, and Cardiovascular Disease. Diabetes. 2007; 56:2655-2667.

13. Taheri S, Lin L, Austin D, Young T, Mignot E. Short sleep duration is associated with reduced leptin, elevated ghrelin, and increased body mass index. PLoS Med. 2004;1:210-7.

14. Pulsford RM, Stamatakis E, Britton AR, Brunner EJ, Hillsdon MM. Sitting behavior and obesity: Evidence from the Whitehall II study. Am J Prev Med. 2013:44:132-8.

15. Pedisic Z, Grunseit A, Ding D, Chau JY, Banks E, Stamatakis E, Jalaludin BB, Bauman AE. High sitting time or obesity: Which came first? Bidirectional association in a longitudinal study of 31,787 Australian adults. Obesity. 2014; 22:2126-30.

16. Blanck HM, McCullough ML, Patel AV, Gillespie C, Calle EE, Cokkinides VE, Galuska DA, Khan LK, Serdula MK. Sedentary behavior, recreational physical activity, and 7-year weight gain among postmenopausal U.S. women. Obesity (Silver Spring). 2007;15:1578-88.

17. Inoue S, Sugiyama T, Takamiya T, Oka K, Owen N, Shimomitsu T. Television viewing time is associated with overweight/obesity among older adults, independent of meeting physical activity and health guidelines. J Epidemiol. 2012;22:50-6.

18. Hu FB, Li TY, Colditz GA, Willett WC, Manson JE. Television watching and other sedentary behaviors in relation to risk of obesity and type 2 diabetes mellitus in women. JAMA. 2003;289:1785-91.

19. Young T, Peppard PE, Taheri S. Excess weight and sleep-disordered breathing. J Appl Physiol. 2005;99:1592-9.

20. Patel SR, Blackwell T, Redline S, Ancoli-israel S, Cauley JA, Hillier TA, Lewis CE, Orwoll ES, Stefanick ML, Taylor BC, Yaffe K, Stone KL. The Association between Sleep Duration and Obesity in Older Adults. Int J Obes. 2009;32: 1825-34.

21. Kripke DF, Garfinkel L, Wingard DL, Klauber MR, Marler MR. Mortality Associated With Sleep Duration and Insomnia. Arch Gen Psychiatry. 2002;59:131.

22. King K, Meader N, Wright K, Graham H, Power C, Petticrew M, White M, Sowden AJ. Characteristics of interventions targeting multiple lifestyle risk behaviours in adult populations: a systematic scoping review. PLoS One. 2015;10:e0117015

23. UK Biobank: Rationale, design and development of a large-scale prospective resource [http://www.ukbiobank.ac.uk/resources/]. Accessed Jan 2014.

24. Craig $C L$, Marshall $A L$, Sjöström M, Bauman AE, Booth ML, Ainsworth BE, Pratt M, Ekelund U, Yngve A, Sallis JF, Oja P. International physical activity questionnaire: 12-country reliability and validity. Med Sci Sports Exerc. 2003; 35:1381-95.

25. IPAQ. Guidelines for Data Processing and Analysis of the International Physical Activity Questionnaire (IPAQ) - Short and Long Forms. 2005. p. 1-15.

26. Wilmot EG, Edwardson CL, Achana FA, Davies MJ, Gorely T, Gray LJ, Khunti $\mathrm{K}$, Yates T, Biddle SJH. Sedentary time in adults and the association with diabetes, cardiovascular disease and death: systematic review and metaanalysis. Diabetologia. 2012;55:2895-905.

27. Bain C, Witschi J, Hennekens CH, Speizer FE. Reproducibility and validity of a semiquantitative food frequency questionnaire. 1985. p. 122.

28. Public Health England. Your Guide to Eatwell Plate Helping You Eat a Healthier Diet. 2014

29. Caulfield M, Munroe P, Pembroke J, Samani N, Dominiczak A, Brown M, Benjamin N, Webster J, Ratcliffe P, O'Shea S, Papp J, Taylor E, Dobson R, Knight J, Newhouse S, Hooper J, Lee W, Brain N, Clayton D, Lathrop GM, Farrall $\mathrm{M}$, Connell J. Genome-wide mapping of human loci for essential hypertension. Lancet (London, England). 2003;361:2118-23.

30. WHO: Physical Status: The Use and Interpretation of Anthropometry. Report of a WHO Expert Committee. WHO Technical Report Series 854. 1995.

31. Shan Z, Ma H, Xie M, Yan P, Guo Y, Bao W, Rong Y, Jackson CL, Hu FB, Liu L. Sleep duration and risk of type 2 diabetes: a meta-analysis of prospective studies. Diabetes Care. 2015;38:529-37.

32. WHO. WHO: Global Recommendations on Physical Activity for Health. 2010.

33. Health and Social Care Information Centre. Health Survey for England-2007: Healthy Lifestyles: Knowledge, Attitudes and Behaviour. 2008.
34. Golubic R, Wijndaele K, Sharp SJ, Simmons RK, Griffin SJ, Wareham NJ, Ekelund $U$, Brage $S$. Physical activity, sedentary time and gain in overall and central body fat: 7-year follow-up of the ProActive trial cohort. Int J Obes. 2015:39:142-8.

35. Sugiyama T, Healy GN, Dunstan DW, Salmon J, Owen N. Joint associations of multiple leisure-time sedentary behaviours and physical activity with obesity in Australian adults. Int J Behav Nutr Phys Act. 2008;5:1-6.

36. Bauman AE, Chau JY, Ding D, Bennie J. Too Much Sitting and CardioMetabolic Risk: An Update of Epidemiological Evidence. Curr Cardiovasc Risk Rep. 2013;7:293-8.

37. Public Health England. Everybody Active, Every Day. An Evidence Based Approach to Physical Activity. 2014.

38. Spiegel K, Leproult R, Van Cauter E. Impact of sleep debt on metabolic and endocrine function. Lancet. 1999;354:1435-9.

39. Chastin SFM, Palarea-Albaladejo J, Dontje ML, Skelton DA. Combined effects of time spent in physical activity, sedentary behaviors and sleep on obesity and cardio-metabolic health markers: A novel compositional data analysis approach. PLoS One. 2015;10:1-37.

40. Lichtman SW, Pisarska K, Berman ER, Pestone M, Dowling H, Offenbacher E, Weisel H, Heshka S, Matthews DE, Heymsfield SB. Discrepancy between selfreported and actual caloric intake and exercise in obese subjects. N Engl J Med. 1992:327:1893-8.

41. Dyrstad SM, Hansen BH, Holme IM. Anderssen S a: Comparison of selfreported versus accelerometer-measured physical activity. Med Sci Sports Exerc. 2014;46:99-106.

42. Clark BK, Sugiyama T, Healy GN, Salmon J, Dunstan DW, Owen N. Validity and reliability of measures of television viewing time and other nonoccupational sedentary behaviour of adults: a review. Obes Rev. 2009;10:7-16.

\section{Submit your next manuscript to BioMed Central and we will help you at every step:}

- We accept pre-submission inquiries

- Our selector tool helps you to find the most relevant journal

- We provide round the clock customer support

- Convenient online submission

- Thorough peer review

- Inclusion in PubMed and all major indexing services

- Maximum visibility for your research

Submit your manuscript at www.biomedcentral.com/submit
Biomed Central 